\title{
BMJ Open Regional and hospital variation in commonly performed paediatric otolaryngology procedures in the Netherlands: a population-based study of healthcare utilisation between 2016 and 2019
}

Juliëtte J C M van Munster (1) , , ,2 Joost J G Wammes (D) , ${ }^{3}$ Rolf H Bremmer, ${ }^{3}$ Amir H Zamanipoor Najafabadi (1) , ${ }^{2}$ Raphael J Hemler, ${ }^{4}$ Wilco C Peul (D) , ${ }^{2}$ Wilbert B van den Hout (D) , ${ }^{5}$ Peter Paul G van Benthem (D) ${ }^{1}$

To cite: van Munster JJCM, Wammes JJG, Bremmer RH, et al. Regional and hospital variation in commonly performed paediatric otolaryngology procedures in the Netherlands: a population-based study of healthcare utilisation between 2016 and 2019. BMJ Open 2021;11:e046840. doi:10.1136/ bmjopen-2020-046840

- Prepublication history and additional supplemental material for this paper are available online. To view these files, please visit the journal online (http://dx.doi.org/10.1136/ bmjopen-2020-046840).

Received 12 November 2020 Accepted 09 June 2021

Check for updates

(C) Author(s) (or their employer(s)) 2021. Re-use permitted under CC BY-NC. No commercial re-use. See rights and permissions. Published by BMJ.

For numbered affiliations see end of article.

Correspondence to

Ms Juliëtte J C M van Munster; j.j.c.m.van_munster@lumc.nl

\section{ABSTRACT}

Objective In the past few decades, there has been an increase in high-quality studies providing evidence on the effectiveness of commonly performed procedures in paediatric otolaryngology. We believe that now is the time to re-evaluate the care process. We aimed to analyse (1) the regional variation in incidence and referrals of adenoidectomies, tonsillectomies and ventilation tube insertions in children in the Netherlands between 2016 and 2019, (2) whether regional surgical rates, referral rates and in-hospital surgical rates were associated with one another, and (3) the hospital variation in healthcare costs, which indicates the utilisation of resources. Design Repeated cross-sectional analysis.

Setting Four neighbouring Dutch provinces comprising 2.8 million inhabitants and 14 hospitals.

Participants Children aged $0-15$ years.

Outcome measures We analysed variation in regional surgical rates and referral rates per 1000 inhabitants and in-hospital surgical rates per 1000 clinic visitors, adjusted for age and socioeconomic status. Furthermore, the relationships between referral rates, regional surgical rates and in-hospital surgical rates were estimated. Lastly, variation in resource utilisation between hospitals was estimated.

Results Adenoidectomy rates differed sixfold between regions. Twofold differences were observed for adenotonsillectomy rates, ventilation tube insertion rates and referral rates. Referral rates were negatively associated with in-hospital surgical rates for adenotonsillectomies, but not for adenoidectomies and ventilation tube insertions. In-hospital surgical rates were positively associated with regional rates for adenoidectomies and adenotonsillectomies. Significant variation between hospitals was observed in costs for all resources.

Conclusions We observed low variation in tonsillectomies and ventilation tube insertion and high variation in adenoidectomies. Indications for a tonsillectomy and ventilation tube insertion are well defined in
Strengths and limitations of this study

- A strength of this study is the use of a large administrative data set covering all the hospitals in the investigated area over multiple years.

- We used various robust measurements on different geographical levels over multiple years to quantify and explain the variation.

- A limitation of the study is the lack of access to clinical data to investigate disease severity.

- We were unable to investigate treatment outcomes.

- The appropriate surgical rate in the Netherlands is unknown, which hampers conclusions regarding overtreatment or undertreatment in our data.

Dutch guidelines, whereas this is not the case for an adenoidectomy. Lack of agreement on indications can be expected and high-quality effectiveness research is required to improve evidence-based guidelines on this topic.

\section{INTRODUCTION}

Paediatric otolaryngology procedures were the first for which very high regional variation was described by Glover, ${ }^{1}$ who found 10 -fold differences in tonsillectomy rates between regions in 1938. This variation could not be explained by differences in patient needs and preferences, and hence was possibly driven by differences in physicians' beliefs about indications for surgery and by lack of effectiveness research. Following Glover's ${ }^{1}$ publication, studies in numerous countries consistently identified and described high volumes and unwarranted regional variation in the utilisation of tonsillectomy, adenoidectomy and ventilation tube insertion in children. ${ }^{23}$ 
In the past few decades, there has been an increase in high-quality studies providing evidence on the effectiveness of adenoidectomies, tonsillectomies and ventilation tube insertions; consequently, indications for surgery have become more accurately defined. ${ }^{4-14}$ Previous research of our group already showed a nationwide decrease in the number of tonsillectomies and adenoidectomies between 2005 and 2018, which was associated with a decrease of annual healthcare and societal costs. ${ }^{15}$ Therefore, we believe that now is the right moment to analyse current practice variation in these procedures, since this is another important step in re-evaluating the care process. $^{1617}$

Evaluation and reduction of practice variation at a systemic level is complicated since it requires combining population data and hospital data. Previous studies mainly identified variation, ${ }^{2} 31819$ but hardly any study has been able to correlate practice variation to explanatory factors. For example, practice variation in the Netherlands might be associated with the fact that in the Netherlands general practitioners (GPs) are gatekeepers for medical specialist care, and referral by a GP is needed before patients can receive hospital care. ${ }^{20}$ Consequently, regional variation in surgical rates can be caused by variation in GP referral rates as well as by variation in specialist care (ie, a physician's choice to perform surgery vs watchful waiting). Understanding the source of variation can support an effective policy to reduce unwarranted variation, increase health outcomes and reduce expenditures. ${ }^{21} 22$

Another limitation in the literature is that most articles focused on unwarranted variation in surgical rates, whereas variation in supply-sensitive care might also be important in these patient groups. Unwarranted practice variation can be divided into three categories: underutilisation of evidence-based interventions, differences in preference-sensitive care and supply-sensitive care. ${ }^{23}$ Preference-sensitive care includes treatments choices that are (partly) based on patients' preferences, whereas supply-sensitive care refers to healthcare utilisation whose frequency depends on availability and is not based on scientific evidence. It includes diagnostics, hospitalisation and physician visits. ${ }^{24}$ Higher healthcare utilisation is unrelated to quality of care and hence reducing supplysensitive care may yield substantial savings, but it requires different strategies from reducing variation in preferencesensitive care. ${ }^{2526}$

The aim of the present study was (1) to establish the current regional variation in referral rates for otitis media, diseases of the tonsils and obstructive sleep apnoea syndrome (OSAS), and regional and in-hospital variations of adenoidectomies, tonsillectomies and ventilation tube insertions in children; (2) to determine whether regional referral rates and in-hospital surgical rates were associated with regional referral rates, and whether regional referral rates were associated with in-hospital surgical rates; and (3) to assess the hospital variation in healthcare costs, which indicates utilisation of resources.

\section{METHODS}

\section{Study design and data sources}

We conducted a retrospective cross-sectional analysis of regional practice variation in four neighbouring provinces in the Netherlands between 2016 and 2019, combining two databases. Firstly, we used a database provided by LOGEX (Amsterdam, The Netherlands). This database covers $100 \%$ of the hospital data in the four provinces under study and was used to extract hospital data. The region comprises 2.8 million inhabitants and 14 hospitals, including one university hospital. No private or independent treatment centres for ear, nose and throat (ENT) services are based in these four provinces. The retrieved benchmark database includes a variety of information, such as the start and end dates of treatment, doctor-patient contacts, performed diagnostics, surgical interventions, diagnosis treatment codes (DBC), dates of admission and hospitalisation. These patient data are combined into care products (so-called 'DBC-DOT Zorgproducten'), which are comparable with diagnosisrelated groups. Recent studies showed that administrative databases, including the LOGEX database, are valid data sources and can be used for quality assessment of healthcare in the Netherlands. ${ }^{27}{ }^{28}$ We retrieved data on age (per year), sex, Charlson Comorbidity Index (CCI $)^{29}$, and four-digit postal codes from this data set.

Second, we used the online database of Statistics Netherlands $(\mathrm{CBS})^{30}$ to extract aggregated numbers of inhabitants. This database was also used to derive socioeconomic status (SES) based on patients' four-digit postal code (inhabitants per 1-year age groups) and number of inhabitants aged $0-15$ years per four-digit postal code. Based on status scores matching the four-digit postal codes, we defined low, middle and high SES.

This study was reported according to the 'Strengthening the Reporting of Observational Studies in Epidemiology' statement. ${ }^{31}$

\section{Study population and data classification}

Patient inclusion was based on age $(<16$ years), patient's postal code (living within the four provinces) and at least one consultation between 1 January 2016 and 31 December 2019 for one of the following diagnosis treatment combination (DBC) codes: 13 (acute otitis media, otitis media with effusion or tube dysfunction), 52 (diseases of the tonsils) or 59 (OSAS). We used multiple DBC codes because these codes all capture indications for surgery. Furthermore, some indications are similar for all three procedures or patients can experience multiple complaints. Registration can depend on which indication the patient experienced as the most severe ${ }^{32}$ (figure 1).

First, patients were classified as patients who underwent adenotonsillectomy if they had only received care product 32320 (tonsillectomy with or without adenoidectomy in children aged 0-10 years) or care product 32321 (tonsillectomy with or without adenoidectomy in children aged 11-15 years). Second, patients were classified as patients who underwent ventilation tube insertion if 


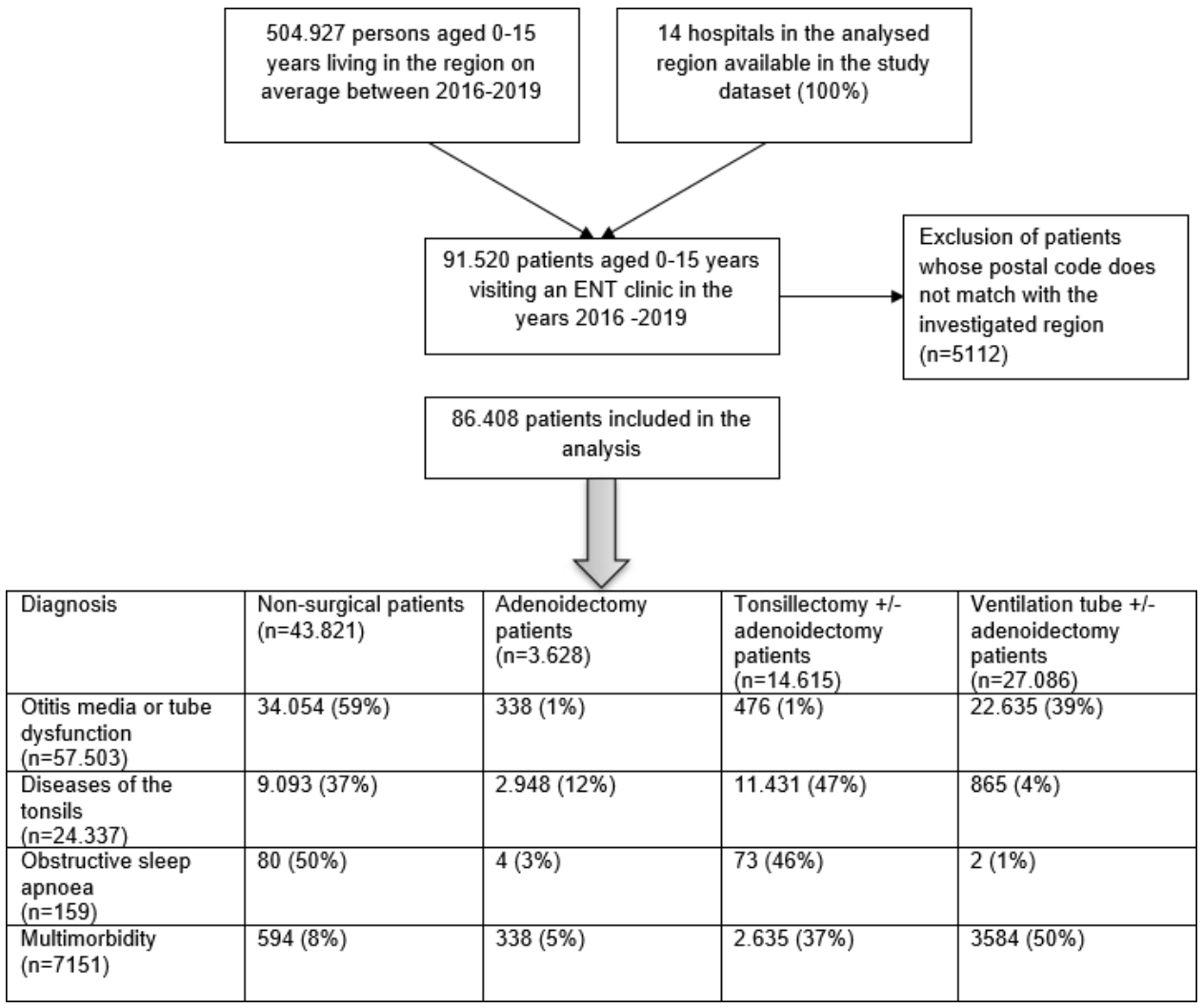

Figure 1 Flow chart of patient selection. ENT, ear, nose and throat.

they had received care product 31802 (ventilation tube insertion with or without adenoidectomy). Lastly, patients were classified as patients who solely underwent adenoidectomy if they had only received care product 32330 (adenoidectomy). To prevent finding variation based on registration differences, patients were excluded from the adenoidectomy group if they had received adenoidectomy and another procedure (tonsillectomy or ventilation tube insertion) on the same day. Care products for tonsillectomy and ventilation tube insertion include the description 'with or without adenoidectomy' since these procedures are often performed together. Some hospitals register both procedures, whereas others only register tonsillectomy or ventilation tube insertion. All the remaining patients were categorised as non-surgical patients.

The study inclusion criteria and the data classification for this study were reviewed with an ENT surgeon in our hospital and three representatives from the Dutch Association of ENT Surgery.

\section{Calculation of adjusted rates}

We calculated the following rates: adjusted surgical and referral rates per 1000 inhabitants aged $0-15$ years living in a postal code region (denominator extracted from the CBS database), adjusted surgical rates per 1000 inhabitants aged $0-15$ years living in a hospital service area (HSA) (denominator extracted from the CBS database and LOGEX database), and adjusted surgical rates per 1000 hospital visitors aged $0-15$ years (denominator extracted from the LOGEX database) registered with DBC 13, 52 or 59 (ie, the treatment choice made by the otolaryngologist if a child was referred to the hospital). We will from now on refer to surgical or referral rates per 1000 inhabitants in a postal code region as 'PC-2 surgical rates' and 'PC-2 referral rates', to surgical rates per 1000 inhabitants in an HSA as 'HSA surgical rates' and to surgical rates per 1000 hospital visitors as 'in-hospital surgical rates'. Methods to calculate HSAs and adjusted surgical rates were thoroughly reviewed with members of the Dutch National Scientific ENT Society.

\section{PC-2 surgical rates and PC-2 referral rates}

Regions were defined by two-digit postal code areas. SESadjusted and age-adjusted surgical rates and referral rates per 1000 inhabitants were calculated with the indirect standardisation method used in the Dartmouth Atlas Project ${ }^{33}$ using the following formula:

$$
\begin{aligned}
& \left(\frac{\text { Observed numbers in postal code are } a_{z}}{\text { Expected numbers in postal code area }}\right) \\
& \times \text { mean rate per } 1000 \text { inhabitants }(0-15 \text { years })
\end{aligned}
$$

Rates per 1000 inhabitants were calculated by multiplying the observed/expected rate with the average rate in the reference population (ie, all four provinces under investigation). The expected number of procedures or referrals in a postal code area $(z)$ was based on the age and SES distribution in this postal code area $(z)$ and on the average probability of receiving surgery per 1-year age 
group and per SES group (low, middle, high) in the four provinces under investigation.

\section{HSA surgical rates}

In the Netherlands, there is a dense network of hospitals, and in most of the regions people can choose between multiple hospitals at acceptable distance from their homes. In such circumstances, the plurality rule may distort the treatment patterns of individual ENT clinics, which we are interested in. Therefore, HSAs were calculated proportionally to the patient flow from four-digit postal codes. All persons living in a four-digit postal code area (CBS data set) were assigned to a hospital using the patient flow ratio from four-digit postal codes to the hospital (LOGEX data set) between 2016 and 2019. A fictitious example explaining this method can be found in online supplemental table 1. Subsequently, SES-adjusted and age-adjusted regional surgical rates per 1000 inhabitants were calculated with the following formula:

$$
\begin{aligned}
& \left(\frac{\text { Observed numbers in Hospital Service Areaz }}{\text { Expected numbers in Hospital Service Area }}\right) \times \\
& \text { mean procedure rate per } 1000 \text { inhabitants }(0-15 \text { years })
\end{aligned}
$$

The expected number of procedures in an $\operatorname{HSA}(z)$ was based on the age and SES distribution in this $\operatorname{HSA}(z)$ and on the average probability of receiving surgery per age (per year) and per SES group.

\section{In-hospital surgical rates}

SES-adjusted and age-adjusted surgical rates per 1000 clinic visitors were calculated using the following formula:

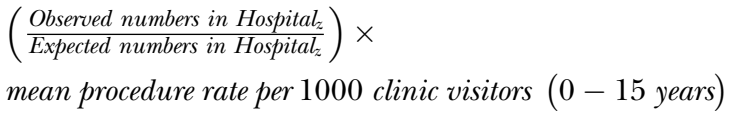

The expected number of procedures in a hospital(z) was based on the age and SES distribution in this hospital(z) and on the probability of receiving surgery per 1-year age group and per SES group (low, middle, high) if referred to a hospital (ie, if DBC 13, 52 or 59 was registered).

\section{Analyses}

For all three procedures, we generated dot plots of adjusted HSA surgical rates per 1000 inhabitants. Additionally, we calculated the extreme quotient (EQ) and its 5th-95th percentile, the interquartile ratio (IqR) and the coefficient of variation $(\mathrm{CoV})$. The $\mathrm{EQ}$ is the ratio between the highest and the lowest regional surgical rate, which is very intuitive but prone to outliers. The IqR is calculated by dividing the 75th percentile by the 25th percentile, and the $\mathrm{CoV}$ is calculated by dividing the SD by the mean. We also calculated the systematic component of variation (SCV) using the following formula ${ }^{34}$ :

$$
\mathrm{SCV}=\frac{1}{N}\left(\sum_{k=1}^{i} \frac{(O i-E i)^{2}}{E i^{2}}-\sum_{k=1}^{i} \frac{1}{E i}\right) \times 100
$$

where $N$ is the number of HSAs, $O i$ is the observed number of procedures in a specific region or hospital, and $E i$ is the expected number of procedures in this same region or hospital. The SCV is a robust measurement as it estimates the variance between areas (systematic variation) that cannot be accounted for by the variability within each area (random variation). Since the SCV is sensitive for outliers, we also calculated the SCV on the 5th and 95 th percentile. ${ }^{35}$ An SCV lower than 5 was considered 'low variation', whereas an SCV between 5 and 10 was considered high variation, and an SCV higher than 10 was considered very high variation. ${ }^{34}$

In an attempt to explain the observed variation in rates, we estimated the associations between PC-2 surgical rates, PC-2 referral rates and in-hospital surgical rates. We assigned the two-digit postal code areas to the hospitals to which most children were referred. If multiple two-digit postal code areas referred to the same hospital, those areas were analysed together. The association between rates was measured using the Pearson correlation coefficient and $\mathrm{r}^{2}$, which represents the proportion of variance that is explained by the independent variable.

\section{Cost analyses}

Information on costs at the patient level (ie, treatment, diagnostics, consultations, inpatient clinic days) was extracted from the LOGEX database to indicate resource use. Costs were calculated by multiplying the delivered healthcare activities with the corresponding LOGEX benchmark unit prices. ${ }^{36}{ }^{37}$ We compared the lowest and the highest average crude costs between hospitals, including the 25th and 75th percentile.

Furthermore, we analysed differences between hospitals in average adjusted costs using a generalised linear mixed effects model. The hospital code was included as a random effect, while age, comorbidities, SES and diagnosis were included as fixed effects. To check whether the results were influenced by the skewed distribution of costs, sensitivity analysis was performed with a second model using log-transformed total costs.

\section{Analytical approach}

Continuous variables were reported as mean with SD or median with interquartile ranges (in case of nonparametric data). Costs were reported as average crude costs per patient in euros $(€)$. Missing data patterns were analysed for all variables, and missing data were imputed using multiple imputation (10 imputation sets), using treatment, age, SES and sex as predictors. Since we linked two databases (LOGEX data set and CBS data set), practice variation scores were calculated using Microsoft Excel V.2016. All other analyses were performed with R V.3.6.1.

\section{RESULTS}

We identified 86408 unique paediatric patients living in the four Dutch provinces under investigation who had visited an ENT surgeon with diseases of the tonsils, complaints of otitis media or OSAS between 2016 and 2019. These patients constitute $16 \%$ of all children aged $0-15$ years living in this area. Figure 1 shows the flow chart of the data selection process. The number of procedures 
Table 1 Baseline data of all patients aged 0-15 years visiting an ENT clinic in 2016-2019

$\begin{array}{ll}\begin{array}{l}\text { Non-surgical } \\ \text { treatment }(n=43\end{array} & \begin{array}{l}\text { Surgical } \\ \text { treatment } \\ (n=42587)\end{array}\end{array}$

\begin{tabular}{|c|c|c|}
\hline Age $^{*}$, mean (SD) & $6.2(3.8)$ & $5.0(2.9)$ \\
\hline \multicolumn{3}{|l|}{$\begin{array}{l}\text { Socioeconomic status, } \\
\mathrm{n}(\%)\end{array}$} \\
\hline Low & $23082(53)$ & $22520(53)$ \\
\hline Middle & $13270(31)$ & $12917(30)$ \\
\hline High & $7469(17)$ & $7150(17)$ \\
\hline \multicolumn{3}{|l|}{ Sex, n (\%) } \\
\hline Male & $24369(56)$ & $23955(56)$ \\
\hline Female & $19452(44)$ & $18632(44)$ \\
\hline \multicolumn{3}{|c|}{ Charlson Comorbidity Index, n (\%) } \\
\hline 0 & $41704(95)$ & $40477(95)$ \\
\hline 1 & $2008(5)$ & $2024(5)$ \\
\hline$>2$ & $109(0)$ & $86(0)$ \\
\hline \multicolumn{3}{|l|}{ Diagnoses $^{\star}, \mathrm{n}(\%)$} \\
\hline $\begin{array}{l}\text { Otitis media or tube } \\
\text { dysfunction }\end{array}$ & $34054(78)$ & $23087(54)$ \\
\hline $\begin{array}{l}\text { Diseases of the } \\
\text { tonsils }\end{array}$ & $9093(21)$ & $14831(35)$ \\
\hline $\begin{array}{l}\text { Obstructive sleep } \\
\text { apnoea }\end{array}$ & $80(0)$ & $77(0)$ \\
\hline Multiple diagnoses & $594(1)$ & $4592(11)$ \\
\hline
\end{tabular}

*Indicates a statistically significant difference $(p<0.05)$ between groups.

ENT, ear, nose and throat.

per category is higher than the total number of paediatric patients in the region who visited an ENT surgeon, since patients were counted for two or three categories if they underwent two or three procedures between 2016 and 2019 but not on the same day. In total, 234 of these extra procedures were included. Patients who underwent

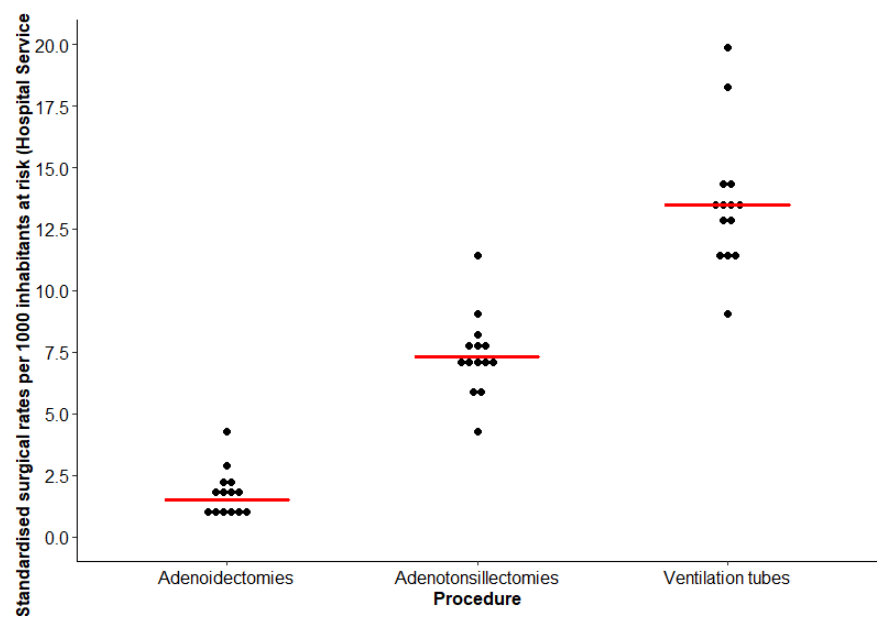

Figure 2 Dot plots of adjusted surgical rates per 1000 children aged 0-15 years living in the hospital service areas. adenotonsillectomy and ventilation tube insertion on the same day $(n=1822)$ were also counted for both surgeries.

Furthermore, 667 patients (1\% of all patients visiting the hospital) underwent adenoidectomy, adenotonsillectomy and ventilation tube insertion on the same day, 6903 patients $(8 \%)$ underwent adenoidectomy and ventilation tube insertion on the same day, and 1278 patients (1\%) underwent adenoidectomy and tonsillectomy on the same day. As explained earlier, adenoidectomy was ignored in these patients as this procedure might already have been registered as part of the care activities for the adenotonsillectomy or the ventilation tube insertion.

In total, fewer than $5 \%$ of the data were missing, and all missing data concerned the CCI. For this variable, data were missing for 13041 patients (15\%). Those data were imputed using treatment, age, SES and sex as predictors. The baseline characteristics of all the included patients are presented in table 1.

\section{Variation in regional surgical rates and in in-hospital surgical rates}

Figure 2 shows the dot plots of age-adjusted and SESadjusted HSA surgical rates per 1000 inhabitants aged $0-15$ years. The red lines represent the median rate. The median rate was $1.5(1.2-2.1)$ per 1000 inhabitants at risk of adenoidectomies, 7.3 (6.7-7.9) per 1000 inhabitants at risk of adenotonsillectomies and 13.5 (12.0-14.1) per 1000 inhabitants at risk of ventilation tube insertion. Furthermore, the median rate was 38.1 (28.9-45.2) per 1000 consultations for adenoidectomies, 159.2 (146.0198.0) per 1000 consultations for adenotonsillectomies and 315.9 (280.9-344.9) per 1000 consultations for ventilation tube insertion.

Practice variation outcomes are presented intable 2 (two-digit postal code areas) and table 3 (HSAs and hospitals). Furthermore, associations between PC-2 rates, HSA rates and in-hospital surgical rates over all the years of the study period are illustrated in figure 3 .

\section{Adenoidectomy}

Overall, we observed very high variation for adenoidectomy rates in PC-2 surgical rates, HSA surgical rates and hospital surgical rates. We observed approximately sevenfold differences between PC-2 adenoidectomy rates. For both HSA surgical rates and in-hospital surgical rates, sixfold differences were observed. Although differences decreased when values below the 5th and above the 95th percentile were removed, persistent high variation was found for adenoidectomy rates.

\section{Adenotonsillectomy}

We observed twofold differences for adenotonsillectomy rates in two-digit postal code areas and threefold differences for adenotonsillectomy rates in HSAs. The SCVs revealed low variation in both PC-2 adenotonsillectomy rates and HSA adenotonsillectomy rates. In-hospital surgical rates differed threefold and the 
Table 2 Regional variation in surgical rates and referrals from 2016 to 2019 in children aged 0-15 years in two-digit postal code areas

$\begin{array}{lllllll}\text { Average rate } & \mathrm{EQ} & \mathrm{EQ}_{5-95} & \text { IqR } & \text { CoV } & \text { SCV } & \text { SCV }_{5-95}\end{array}$

Regional surgical rates per 1000 inhabitants aged 0-15 years (two-digit postal code area)

Adenoidectomy

\begin{tabular}{|c|c|c|c|c|c|c|c|}
\hline 2016 & 1.9 & 9.5 & 2.7 & 1.8 & 0.5 & $26.3^{*}$ & 4.8 \\
\hline 2017 & 1.8 & 10.5 & 3.8 & 1.8 & 0.7 & $39.1^{*}$ & $6.5 \dagger$ \\
\hline 2018 & 1.8 & 7.4 & 3.4 & 2.2 & 0.5 & $16.0^{*}$ & $6.9+$ \\
\hline 2019 & 1.8 & 6.2 & 3.8 & 1.9 & 0.5 & $21.2^{*}$ & $8.4 \dagger$ \\
\hline All years & 1.8 & 7.2 & 2.6 & 1.9 & 0.5 & $23.4^{*}$ & $7.3+$ \\
\hline \multicolumn{8}{|c|}{ Adenotonsillectomy } \\
\hline 2016 & 7.8 & 2.1 & 1.7 & 1.2 & 0.2 & 2.2 & 0.7 \\
\hline 2017 & 7.8 & 2.4 & 1.6 & 1.2 & 0.2 & 3.2 & 0.7 \\
\hline 2018 & 6.9 & 2.2 & 1.8 & 1.2 & 0.2 & 4.1 & 1.3 \\
\hline 2019 & 6.6 & 2.6 & 1.8 & 1.3 & 0.2 & 3.6 & 1.7 \\
\hline All years & 7.3 & 2.1 & 1.5 & 1.2 & 0.2 & 2.9 & 1.1 \\
\hline \multicolumn{8}{|c|}{ Ventilation tube insertion } \\
\hline 2016 & 13.2 & 2.3 & 1.6 & 1.3 & 0.2 & 3.3 & 1.2 \\
\hline 2017 & 14.2 & 2.2 & 1.6 & 1.4 & 0.2 & 3.2 & 2 \\
\hline 2018 & 13.7 & 2.2 & 1.6 & 1.3 & 0.2 & 2.9 & 1 \\
\hline 2019 & 12.9 & 2 & 1.6 & 1.2 & 0.2 & 2.9 & 1.5 \\
\hline All years & 13.5 & 1.9 & 1.5 & 1.3 & 0.2 & 2.8 & 1.6 \\
\hline \multicolumn{8}{|c|}{ Referral rates per 1000 inhabitants aged $0-15$ years (two-digit postal code area) } \\
\hline 2016 & 44.1 & 2.4 & 1.5 & 1.3 & 0.2 & 2.7 & 1.5 \\
\hline 2017 & 44.5 & 2.6 & 1.5 & 1.3 & 0.2 & 3.1 & 1.5 \\
\hline 2018 & 42.7 & 2.7 & 1.6 & 1.3 & 0.2 & 2.8 & 1.2 \\
\hline 2019 & 41 & 2.2 & 1.5 & 1.4 & 0.2 & 2.7 & 1.6 \\
\hline All years & 43.1 & 2.4 & 1.5 & 1.3 & 0.2 & 2.8 & 1.5 \\
\hline
\end{tabular}

SCV $>3=$ likely due to differences in practice style or 'medical discretion'; $5-10=$ high variation; $>10=$ very high variation .

*Very high variation.

†High variation.

$\mathrm{CoV}$, coefficient of variation; EQ, extreme quotient; IqR, interquartile ratio; SCV, systematic component of variation.

SCVs revealed high variation for these rates. After removing the most extreme values, low variation was observed for all rates except for the in-hospital tonsillectomy rates in 2019.

\section{Ventilation tube insertion}

Ventilation tube insertion rates differed twofold between two-digit postal code areas, HSAs and hospitals. The SCVs revealed very low variation for ventilation tube insertion rates in two-digit postal code areas, HSAs and in-hospital surgical rates over all the years of the study period.

\section{Referrals}

Referral rates differed twofold between two-digit postal code areas. The SCVs revealed low variation between regions.
Associations between regional rates, referral rates and inhospital rates

We could assign all postal code areas to 13 hospitals based on the plurality rule. For one hospital, no postal code area with the highest market share was identified.

Firstly, in-hospital adenoidectomy rates per 1000 clinic visitors were associated with $\mathrm{PC}-2$ adenoidectomy rates and could explain approximately $67 \% \quad\left(\mathrm{r}=0.81, \mathrm{r}^{2}=0.67\right.$, $\mathrm{p}<0.001)$ of the variation in PC-2 adenoidectomy rates. Referral rates were not associated with PC-2 adenoidectomy rates $\left(\mathrm{r}=0.36, \mathrm{r}^{2}=0.13, \mathrm{p}=0.22\right)$ nor with the in-hospital surgical rates $\left(\mathrm{r}=-0.08, \mathrm{r}^{2}=0.01, \mathrm{p}=0.79\right)$.

Secondly, in-hospital adenotonsillectomy rates were associated with PC-2 adenotonsillectomy rates and could explain $44 \%\left(\mathrm{r}=0.66, \mathrm{r}^{2}=0.44, \mathrm{p}=0.01\right)$ of the regional variation. Referral rates were not associated with PC-2 adenotonsillectomy rates $\left(\mathrm{r}=0.21, \mathrm{r}^{2}=0.04, \mathrm{p}=0.50\right)$, but 
Table 3 Variation in surgical rates from 2016 to 2019 in children aged 0-15 years between hospitals and hospital service areas

$\begin{array}{lllllll}\text { Average rate } & \mathrm{EQ} & \mathrm{EQ}_{5-95} & \text { IqR } & \text { CoV } & \text { SCV } & \text { SCV }_{5-95}\end{array}$

Regional surgical rates per 1000 inhabitants aged 0-15 years (hospital service areas)

Adenoidectomy

\begin{tabular}{|llllllll|}
\hline 2016 & 1.9 & 6 & 2.6 & 1.8 & 0.5 & $24.0^{*}$ & $7.5 \dagger$ \\
\hline 2017 & 1.8 & 8 & 3.6 & 2 & 0.6 & $28.3^{*}$ & $11.7^{*}$ \\
\hline 2018 & 1.8 & 5.7 & 3.4 & 2 & 0.5 & $21.2^{*}$ & $10.7^{*}$ \\
\hline 2019 & 1.8 & 5.6 & 3.6 & 1.7 & 0.5 & $18.4^{*}$ & $9.6 \dagger$ \\
\hline All years & 1.8 & 5.7 & 3.2 & 1.8 & 0.5 & $22.4^{*}$ & $9.6 \dagger$ \\
\hline Adenotonsillectomy & & & & & & & \\
\hline 2016 & 7.9 & 2 & 1.7 & 1.2 & 0.2 & 3 & 1.3 \\
\hline 2017 & 7.8 & 3.4 & 1.7 & 1.1 & 0.2 & $5.1 \dagger$ & 1.2 \\
\hline 2018 & 6.9 & 2.7 & 1.5 & 1.2 & 0.2 & 4.6 & 1.2 \\
\hline 2019 & 6.6 & 2.9 & 2.3 & 1.2 & 0.3 & $6.3 \dagger$ & 2.9 \\
\hline All years & 7.3 & 2.5 & 1.6 & 1.2 & 0.2 & 4.2 & 1.4 \\
Ventilation tube insertion & & & & & & & \\
\hline 2016 & 13.2 & 2.7 & 1.6 & 1.1 & 0.2 & 4.8 & 1.8 \\
\hline 2017 & 14.2 & 2.7 & 1.7 & 1.2 & 0.2 & 4 & 1.5 \\
\hline 2018 & 13.7 & 1.9 & 1.8 & 1.1 & 0.2 & 3.8 & 2.1 \\
\hline 2019 & 12.9 & 1.9 & 1.6 & 1.2 & 0.2 & 2.9 & 1.4 \\
\hline All years & 13.5 & 2.2 & 1.6 & 1.2 & 0.2 & 3.8 & 1.7 \\
\hline
\end{tabular}

In-hospital surgical rates per 1000 hospital visitors aged $0-15$ years

Adenoidectomy

\begin{tabular}{llllllll}
2016 & 44 & 6.2 & 2.7 & 1.4 & 0.5 & $18.0^{*}$ & $8.8 \dagger$ \\
2017 & 39 & 8.1 & 3.1 & 2.3 & 0.5 & $19.4^{*}$ & $10.3^{*}$ \\
2018 & 41 & 4.1 & 3.7 & 1.7 & 0.4 & $14.9^{*}$ & $10.0^{*}$ \\
2019 & 43 & 7 & 2.7 & 1.5 & 0.4 & $15.9^{*}$ & $5.8 \dagger$ \\
All years & 42 & 5.8 & 2.4 & 1.6 & 0.4 & $16.9^{*}$ & $5.6 \dagger$ \\
Adenotonsillectomy & & & & & & & \\
2016 & 178 & 1.8 & 1.7 & 1.4 & 0.2 & 4.1 & 2.7 \\
2017 & 176 & 2.9 & 1.8 & 1.3 & 0.3 & $5.8 \dagger$ & 3.1 \\
2018 & 161 & 2.6 & 1.8 & 1.3 & 0.3 & $5.8 \dagger$ & 3.3 \\
2019 & 160 & 2.5 & 2.2 & 1.5 & 0.3 & $7.4 \dagger$ & $5.1 \dagger$ \\
All years & 169 & 2.3 & 1.8 & 1.4 & 0.2 & $5.4 \dagger$ & 3.5 \\
Ventilation tube insertion & & & & & & & \\
2016 & 300 & 2.1 & 1.6 & 1.2 & 0.2 & 3.5 & 2 \\
2017 & 318 & 2.2 & 1.5 & 1.2 & 0.2 & 2.8 & 1.1 \\
2018 & 320 & 1.7 & 1.6 & 1.2 & 0.2 & 2 & 1.2 \\
2019 & 316 & 1.7 & 1.4 & 1.2 & 0.1 & 1.7 & 1 \\
All years & 313 & 1.7 & 1.5 & 1.2 & 0.2 & 2.4 & 1.7 \\
\hline
\end{tabular}

SCV $>3=$ likely due to differences in practice style or 'medical discretion'; 5-10=high variation; $>10=$ very high variation. *Very high variation.

†High variation.

CoV, coefficient of variation; EQ, extreme quotient; IqR, interquartile ratio; SCV, systematic component of variation. 

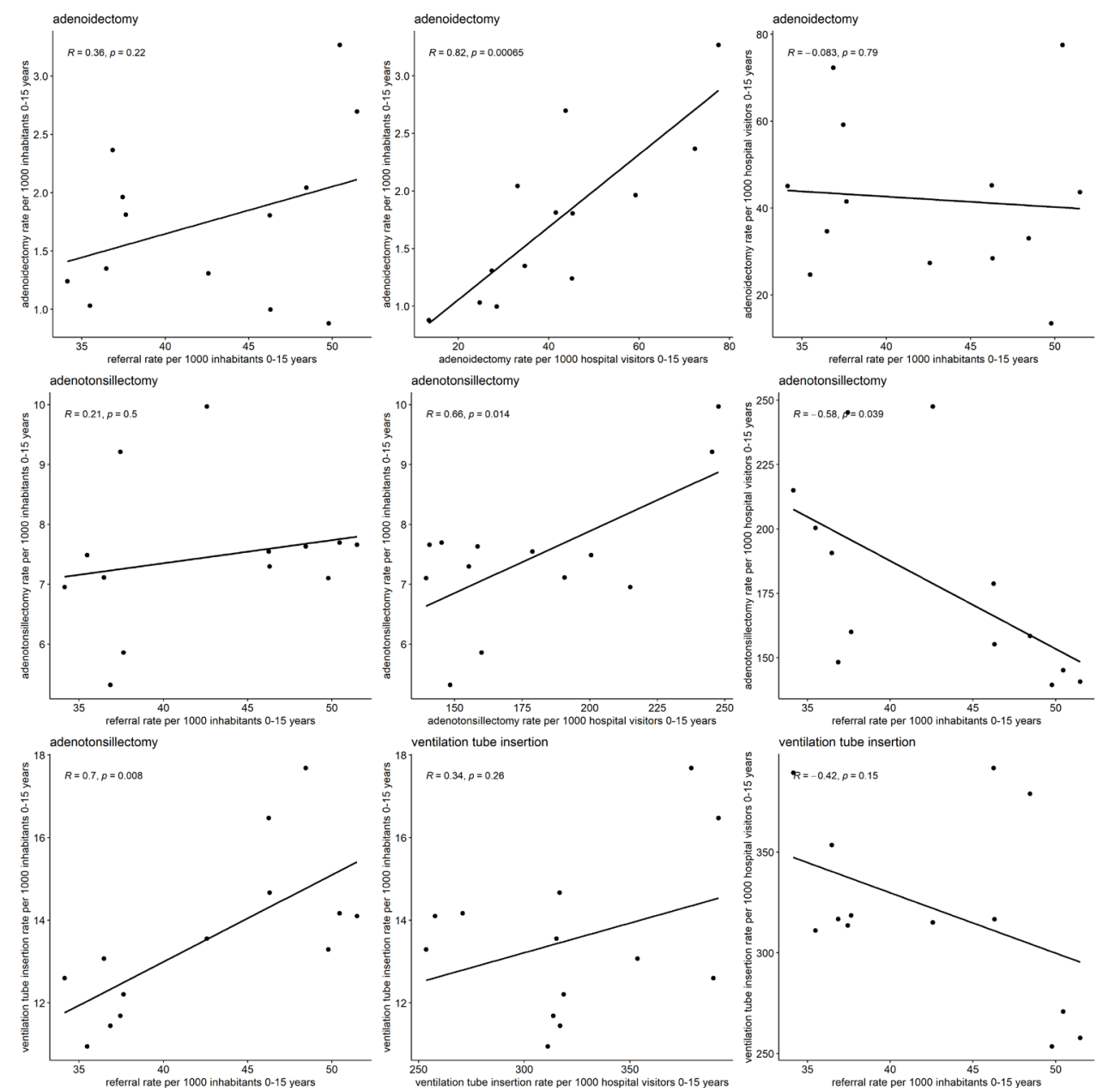

Figure 3 Relationships between referral rates, in-hospital surgical rates and regional surgical rates.

they were negatively associated with in-hospital surgical rates per 1000 clinic visitors $\left(r=-0.58, r^{2}=0.33 p=0.04\right)$.

Thirdly, in-hospital ventilation tube insertion rates were not associated with PC-2 ventilation tube insertion rates $\left(\mathrm{r}=0.34, \mathrm{r}^{2}=0.12, \mathrm{p}=0.26\right)$, whereas referral rates were associated with $\mathrm{PC}-2$ surgical rates and explained approximately $49 \%\left(r=0.70, r^{2}=0.49, p=0.008\right)$ of the regional variation. Referral rates were not associated with in-hospital surgical rates $\left(\mathrm{r}=-0.41, \mathrm{r}^{2}=0.18, \mathrm{p}=0.15\right)$.

\section{Cost analysis and between-hospital variation in care processes}

Average crude costs for surgical patients and non-surgical patients are described in table 4 . In all hospitals, average crude costs for surgical patients were five times (adenoidectomy patients) to seven times (adenotonsillectomy patients) higher than for non-surgically treated patients. These differences were mainly caused by differences in treatment costs and hospitalisation costs. Average total costs varied between hospitals from $€ 123$ to $€ 188$ for the non-surgically treated patient group, from $€ 716$ to $€ 910$ for adenoidectomy patients, from $€ 927$ to $€ 1343$ for adenotonsillectomy patients, and from $€ 709$ to $€ 1058$ for ventilation tube insertion patients. In all four groups of patients, the largest between-hospital differences were found for diagnostics. Between-hospital variation for diagnostics ranged from 13-fold to 26-fold differences. Furthermore, we observed between-hospital differences in costs for treatment, ranging from 1.4-fold differences in adenoidectomy patients to 16 -fold differences in nonsurgically treated patients. For consultations, differences varied between 1.3-fold and 1.7-fold differences. Last, differences in average costs for hospitalisation ranged from 1.4-fold differences in adenoidectomy patients to 49-fold differences in non-surgically treated patients. Adjusted for age, SES and CCI, variation in costs between hospitals was observed in all groups, except for treatment costs in non-surgically treated patients and treatment costs, hospitalisation costs, and total costs in adenoidectomy patients. Sensitivity analysis with a second model using log-transformed total costs showed that the results were not influenced by the skewed distribution of costs.

\section{DISCUSSION}

In the present study, we aimed to analyse the current practice variation in the entire care process for children with otitis media, diseases of the tonsils and OSAS; analyse regional and in-hospital variations in adenoidectomies, tonsillectomies and ventilation tube insertions in 
Table 4 Between-hospital variation in crude average costs per patient

\begin{tabular}{|c|c|c|c|c|c|}
\hline & Mean† & Percentage of total cost & Min-maxł & P25-P75 & $\mathbf{P}$ value§ \\
\hline \multicolumn{6}{|c|}{ Non-surgically treated patients $(n=43821)$} \\
\hline Treatment & 3 & 2 & $0-16$ & $1-4$ & 0.11 \\
\hline Diagnostics & 22 & 13 & $1-20$ & $7-12$ & $0.01^{*}$ \\
\hline Hospitalisation & 8 & 6 & $1-49$ & $10-27$ & $0.04^{*}$ \\
\hline \multicolumn{6}{|c|}{ Adenoidectomy patients $(\mathrm{n}=3628)$} \\
\hline Treatment & 244 & 30 & $203-287$ & $218-240$ & 0.16 \\
\hline Consultations & 135 & 17 & $102-180$ & $123-146$ & $0.03^{*}$ \\
\hline Diagnostics & 20 & 2 & $3-38$ & $11-19$ & $0.02^{*}$ \\
\hline Hospitalisation & 416 & 51 & $370-525$ & $395-420$ & $0.06^{*}$ \\
\hline \multicolumn{6}{|c|}{ Adenotonsillectomy patients $(n=14615)$} \\
\hline Treatment & 474 & 44 & $388-799$ & $409-507$ & $0.01^{*}$ \\
\hline Consultations & 132 & 12 & $103-172$ & $123-141$ & $0.01^{*}$ \\
\hline Diagnostics & 8 & 1 & $0-26$ & $4-11$ & $0.01^{*}$ \\
\hline Hospitalisation & 455 & 43 & $411-658$ & $431-472$ & $0.02^{*}$ \\
\hline Total cost & 1070 & 100 & $927-1343$ & $1003-1128$ & $0.01^{*}$ \\
\hline \multicolumn{6}{|c|}{ Ventilation tube patients $(n=27086)$} \\
\hline Treatment & 355 & 38 & $221-406$ & 290-378 & $0.01^{*}$ \\
\hline Consultations & 167 & 18 & $132-208$ & $155-175$ & $0.01^{*}$ \\
\hline Diagnostics & 22 & 2 & $3-64$ & $10-27$ & $0.01^{*}$ \\
\hline
\end{tabular}

*Statistically significant.

†Patient level.

$\ddagger$ Variation in crude average costs between 14 hospitals.

$\S$ Tests homogeneity between hospitals using a generalised linear mixed effects model to adjust costs for age, socioeconomic status and Charlson Comorbidity Index.

children in four provinces in the Netherlands; analyse the association between the various measures; and analyse variations in costs between hospitals, both for surgically treated and non-surgically treated patients.

\section{Statement of principal findings}

Very high regional variation was found for adenoidectomies, which could partly be explained by the differences between treatment choices made by otolaryngologists if a child was referred. GP referral rates were not associated with in-hospital surgical rates.

Conversely, low variation was observed for adenotonsillectomies, but the treatment choices made by the otolaryngologists were associated with GP referral rates. Higher GP referral rates led to lower in-hospital adenotonsillectomy rates. Also, in-hospital surgical rates were positively associated with regional surgical rates.

The lowest variation was observed for ventilation tube insertion. Referral rates were associated with the regional rates but not with the choices made by the otolaryngologists. Moreover, the in-hospital surgical rates were not associated with regional variation.

For all procedures, including the non-surgical treatment of patients, we observed significant variations in healthcare resource utilisation and costs between hospitals with respect to treatment, consultations, diagnostics and clinic days.

\section{Strengths and weaknesses of the study}

To the best of our knowledge, this is the first study that investigated the associations between regional variation, referral rates and treatment choices in the hospital for otolaryngology procedures. We used various measurements which showed similar results, making our conclusions more robust. The outcomes partially explained the variation in surgical rates, which can provide guidance for quality improvement projects. However, numbers of observation (i.e. hospitals) might be too low to draw definitive conclusions. Unfortunately, we were not able to investigate other potential causes of variation, such as 
disease severity, as we used administrative hospital data. Including these factors in future analyses might help to better understand regional variation. Still, the use of administrative data enabled us to perform a populationbased study on 14 hospitals and in multiple years.

\section{Findings in relation to other studies}

Unfortunately, a proper comparison with other studies based on Dutch data is difficult due to limited data availability and to the fact that the papers that reported these data were limited by a range of analytical difficulties, ${ }^{32}$ such as not including all DBCs, which is important since the three relevant codes included in the present study all capture indications for surgery.

Having said that, we found an order of magnitude of variation in adenotonsillectomy rates and ventilation tube insertion rates in our study that is markedly lower than the variation found in many previous studies from other countries. ${ }^{138-40}$ Limited data are available on regional variation in adenoidectomy rates, ${ }^{41}$ which hampers comparison with historical outcomes. Nevertheless, our results showed that the variation in adenoidectomy rates was surprisingly large compared with the variation in adenotonsillectomy rates and ventilation tube insertion rates. The difference in magnitude of variation between the three procedures might be due to the fact that indications for the latter two procedures are well defined in Dutch guidelines, ${ }^{12} 42$ whereas this is not the case for adenoidectomies. This outcome was already predicted in 1973 by Dr Wennberg, ${ }^{43}$ a pioneer of research in unwarranted variations in healthcare practice. Wennberg ${ }^{43}$ argued that if there is agreement on indications for surgery, variation tends to be low. Conversely, professional uncertainty will lead to high practice variation. For adenoidectomy alone, it was recommended not to perform surgery in patients who only have upper respiratory tract infections However, there is a lack of evidence on true evidence-based indications for an adenoidectomy, for example in case of nasal obstruction. ${ }^{1244}$

\section{Clinical implications}

The question arises for which specific patient group adenoidectomy alone is truly necessary and effective. High-quality research on the effectiveness of adenoidectomy alone is warranted to better guide clinicians in the Netherlands and in all other countries.

Another effective approach to reduce practice variation might be audits and feedback on practice variation outcomes. ${ }^{45}$ For example, feedback on adenoidectomy rates might be presented at the hospital level, since our data suggest high practice variation in adenoidectomy rates at the hospital level rather than in the GP referral rates. For adenotonsillectomies, audit and feedback might be warranted at the hospital level as well as the GP level. Even though GPs in certain areas referred many children to a hospital, the referral of these children might not have been appropriate since surgical rates in these areas with more referrals did not significantly differ from surgical rates in areas in which fewer children were referred.

Perhaps the greatest challenge we faced in interpreting our results was that the appropriate surgical rate in children with evidence-based indications for surgery is unknown in the Netherlands. This hampered a conclusion regarding overtreatment or undertreatment of adenoidectomies in our data, which is necessary to better inform improvement policies. For future research, it would be interesting to analyse information from electronic medical records and determine recorded indications for surgery and adherence to guidelines.

Reducing the use of healthcare resources in all hospitals and decreasing practice variation can reduce costs, which is beneficial from both the healthcare perspective and the societal perspective. ${ }^{9} 11$ The largest differences in average costs per patient were due to treatment differences between surgical patients and non-surgical patients, but variation was also observed for all other resources. High utilisation tends to be unrelated to better quality of healthcare, ${ }^{24}{ }^{25}$ which warrants the hypothesis that all hospitals with above-average resource utilisation could decrease their utilisation to the overall average costs per patient (eg, by reducing the number of clinic days by performing day case surgery or by reducing the number of consultations after surgery).

\section{CONCLUSIONS}

In conclusion, our findings showed low variation in ventilation tube insertion rates and adenotonsillectomy rates, but high variation in adenoidectomy rates. The low variation in tonsillectomies and ventilation tube insertions was probably due to the implementation of evidence-based guidelines in the past decades. The high variation in adenoidectomies might indicate a lack of agreement on indications for surgery, and our findings underscore the need for high-quality effectiveness research to improve evidence-based guidelines on this topic. Differences in costs between surgical patients and non-surgical patients were mainly due to treatment choice, but potential savings could also be achieved by reducing the variation in the number of clinic days and consultations between hospitals.

\section{Author affiliations}

${ }^{1}$ Otorhinolaryngology and Head and Neck Surgery, Leiden University Medical Center, Leiden, The Netherlands

${ }^{2}$ University Neurosurgical Center Holland, Leiden University Medical Center, Leiden, The Netherlands

${ }^{3}$ Hospital \& Health Care, LOGEX, Amsterdam, The Netherlands

${ }^{4}$ Otorhinolaryngology, Gelre Hospitals, Apeldoorn, The Netherlands

${ }^{5}$ Biomedical Data Sciences, Leiden University Medical Center, Leiden, The Netherlands

Twitter Juliëtte J C M van Munster @jvmunster, Rolf H Bremmer @rolfbremmer, Amir H Zamanipoor Najafabadi @Amir_Zamanipoor and Wilco C Peul @WilcoPeul

Acknowledgements We would like to acknowledge LOGEX for providing us the data used in the analyses presented in this manuscript. We would like to acknowledge David Colnot and Henk Blom (Dutch ENT Society) for evaluating the 
methodlogy for defining Hospital Service Areas and for calculating adjusted surgical rates.

Contributors PPB is the guarantor of the study. JvM wrote the statistical analysis plan, analysed the data, and drafted and revised the paper. RH, WP, PPB, WH and AHZN supported the conceptualisation and methodology. JW and RB supported the data curation, resources and formal analysis. WH supported the cost analyses. All authors reviewed the manuscript.

Funding The authors have not declared a specific grant for this research from any funding agency in the public, commercial or not-for-profit sectors.

Competing interests None declared.

Patient consent for publication Not required.

Ethics approval The present study complies with the Declaration of Helsinki. The Medical Ethics Committee Leiden Den Haag and Delft reviewed the protocol (N20.001) and decided that approval by the committee was not necessary since participants were not involved in the study and patient anonymity was safeguarded in the database.

Provenance and peer review Not commissioned; externally peer reviewed.

Data availability statement The study brought together existing data obtained upon request and subject to license restrictions. Data may be obtained from a third party (LOGEX) and are not publicly available due to commercially sensitive nature of the research.

Supplemental material This content has been supplied by the author(s). It has not been vetted by BMJ Publishing Group Limited (BMJ) and may not have been peer-reviewed. Any opinions or recommendations discussed are solely those of the author(s) and are not endorsed by BMJ. BMJ disclaims all liability and responsibility arising from any reliance placed on the content. Where the content includes any translated material, BMJ does not warrant the accuracy and reliability of the translations (including but not limited to local regulations, clinical guidelines, terminology, drug names and drug dosages), and is not responsible for any error and/or omissions arising from translation and adaptation or otherwise.

Open access This is an open access article distributed in accordance with the Creative Commons Attribution Non Commercial (CC BY-NC 4.0) license, which permits others to distribute, remix, adapt, build upon this work non-commercially, and license their derivative works on different terms, provided the original work is properly cited, appropriate credit is given, any changes made indicated, and the use is non-commercial. See: http://creativecommons.org/licenses/by-nc/4.0/.

\section{ORCID IDs}

Juliëtte J C M van Munster http://orcid.org/0000-0002-1670-1800

Joost J G Wammes http://orcid.org/0000-0002-8382-7198

Amir H Zamanipoor Najafabadi http://orcid.org/0000-0003-2400-2070

Wilco C Peul http://orcid.org/0000-0001-7274-1447

Wilbert B van den Hout http://orcid.org/0000-0002-6425-0135

Peter Paul G van Benthem http://orcid.org/0000-0002-7946-1912

\section{REFERENCES}

1 Glover JA. The incidence of tonsillectomy in school children:

(Section of epidemiology and state medicine). Proc $R$ Soc Med 1938;31:1219-36.

2 van Beek EL, van Schooten G, Vlieger EJ. Reduceren van praktijkvariatie: budgettaire effecten van scherpere indicatiestelling. Ministerie van Volksgezondheid WeS, Plexus, 2010.

3 Van Den Akker EH, Hoes AW, Burton MJ, et al. Large international differences in (adeno)tonsillectomy rates. Clin Otolaryngol Allied Sci 2004;29:161-4.

4 Marchica CL, Dahl JP, Raol N. What's new with tubes, tonsils, and adenoids? Otolaryngol Clin North Am 2019;52:779-94.

5 Rosenfeld RM, Schwartz SR, Pynnonen MA, et al. Clinical practice guideline: tympanostomy tubes in children--executive summary. Otolaryngol Head Neck Surg 2013;149:8-16.

6 Paradise JL, Bluestone CD, Bachman RZ, et al. Efficacy of tonsillectomy for recurrent throat infection in severely affected children. Results of parallel randomized and nonrandomized clinical trials. N Engl J Med 1984;310:674-83.

7 Paradise JL, Bluestone CD, Colborn DK, et al. Tonsillectomy and adenotonsillectomy for recurrent throat infection in moderately affected children. Pediatrics 2002;110:7-15.

8 van Staaij BK, van den Akker EH, Rovers MM, et al. Effectiveness of adenotonsillectomy in children with mild symptoms of throat infections or adenotonsillar hypertrophy: open, randomised controlled trial. BMJ 2004;329:651.

9 Buskens E, van Staaij B, van den Akker J, et al. Adenotonsillectomy or watchful waiting in patients with mild to moderate symptoms of throat infections or adenotonsillar hypertrophy: a randomized comparison of costs and effects. Arch Otolaryngol Head Neck Surg 2007;133:1083-8.

10 van den Aardweg MTA, Boonacker CWB, Rovers MM, et al. Effectiveness of adenoidectomy in children with recurrent upper respiratory tract infections: open randomised controlled trial. BMJ 2011;343:d5154.

11 Boonacker CWB, van den Aardweg MTA, Broos PH, et al. Immediate adenoidectomy vs initial watchful waiting strategy in children with recurrent upper respiratory tract infections: an economic evaluation. JAMA Otolaryngol Head Neck Surg 2013;139:129-33.

12 Specialisten FM. ZATT-richtlijn (Ziekten adenoid en Tonsillen in de Tweede lijn), 2014. Available: https://richtlijnendatabase.nl/richtlijn/ ziekten_van_adenoid_en_tonsillen_zatt/ziekten_van_adeno_d_en_ tonsillen - startpagina.html [Accessed 09 Apr 2019].

13 van den Aardweg MT, Schilder AG, Herkert E, et al. Adenoidectomy for otitis media in children. Cochrane Database Syst Rev 2010:CD007810.

14 Venekamp RP, Hearne BJ, Chandrasekharan D. Tonsillectomy or adenotonsillectomy versus non-surgical management for obstructive sleep-disordered breathing in children. Cochrane Database Syst Rev 2015;10:Cd011165.

15 van Munster JJCM, Zamanipoor Najafabadi AH, van 't Hooft J, et al. Changes in healthcare utilisation for paediatric tonsillectomy and adenoidectomy in the Netherlands: a population-based study. Clin Otolaryngol 2021;46:347-56.

16 Westert GP, Groenewoud S, Wennberg JE, et al. Medical practice variation: public reporting a first necessary step to spark change. Int J Qual Health Care 2018;30:731-5.

17 Goldschmidt PG. The "Right Rate" of Tonsillectomy. JAMA Otolaryngol Head Neck Surg 2020;146:311.

18 de Melker RAH GJ. Tonsillectomie opnieuw bekeken. Huisarts\&Praktijk 1987;30:79-81.

19 Mackenbach JP. Regionale verschillen in de frequentie van enkele veel voorkomende operaties, 1985. Nederlands Tijdschrift voor Geneeskunde 1990;134:953-7.

20 Groenewegen P. [General practitioners as gatekeepers: Better health care than in countries with self-referral to specialists?]. Ned Tijdschr Geneeskd 2016;160:D88.

21 Wennberg JE. Dealing with medical practice variations: a proposal for action. Health Aff 1984;3:6-33.

22 Birkmeyer JD, Reames BN, McCulloch P, et al. Understanding of regional variation in the use of surgery. Lancet 2013;382:1121-9.

23 Wennberg JE. Unwarranted variations in healthcare delivery: implications for academic medical centres. BMJ 2002;325:961-4.

24 A Dartmouth atlas project topic brief: Supply-Sensitive care: center for the Evaluative clinical sciences.

25 Fisher ES, Wennberg JE. Health care quality, geographic variations, and the challenge of supply-sensitive care. Perspect Biol Med 2003;46:69-79.

26 Miranda E. Unwarranted variations in care: searching for sources and solutions. Virtual Mentor 2014;16:91-3.

27 Eindhoven DC, van Staveren LN, van Erkelens JA, et al. Nationwide claims data validated for quality assessments in acute myocardial infarction in the Netherlands. Neth Heart J 2018;26:13-20.

28 Salet N, Bremmer RH, Verhagen MAMT, et al. Is Textbook Outcome a valuable composite measure for short-term outcomes of gastrointestinal treatments in the Netherlands using hospital information system data? A retrospective cohort study. BMJ Open 2018;8:e019405

29 Charlson M, Szatrowski TP, Peterson J, et al. Validation of a combined comorbidity index. J Clin Epidemiol 1994;47:1245-51.

30 StatLine database. Available: http://statline.cbs.nl [Accessed 02 Jul 2019].

31 von Elm E, Altman DG, Egger M, et al. The strengthening the reporting of observational studies in epidemiology (STROBE) statement: guidelines for reporting observational studies. Int J Surg 2014:12:1495-9.

32 Maassen H. Praktijkvariatie onbewezen. Medisch Contact 2012;38.

33 An example of indirect adjustment the Dartmouth atlas of health care. Available: https://www.dartmouthatlas.org/wp-content/uploads/ indirect_adjustment.pdf

34 McPherson K, Wennberg JE, Hovind OB, et al. Small-area variations in the use of common surgical procedures: an international comparison of new England, England, and Norway. N Engl J Med 1982;307:1310-4. 
35 Diehr P, Cain K, Connell F, et al. What is too much variation? the null hypothesis in small-area analysis. Health Serv Res 1990;24:741-71.

36 Swan Tan S, Bouwmans-Frijters CAM, Hakkaart-van Roijen L. Handleiding voor kostenonderzoek: methoden en referentieprijzen voor economische evaluaties in de gezondheidszorg. Tijdschrift voor gezondheidswetenschappen 2012;90:367-72.

37 Goense L, van Dijk WA, Govaert JA, et al. Hospital costs of complications after esophagectomy for cancer. Eur J Surg Oncol 2017;43:696-702.

38 Appleby J, Raleigh V, Frosini F. Variations in health care. In: The good, the bad and the inexplicable. London: The King's Fund, 2011.

39 Weeks WB, Paraponaris A, Ventelou B. Geographic variation in rates of common surgical procedures in France in 2008-2010, and comparison to the US and Britain. Health Policy 2014;118:215-21.
40 Parker DM, Schang L, Wasserman JR, et al. Variation in utilization and need for tympanostomy tubes across England and new England. J Pediatr 2016;179:178-84.

41 van Munster JJCM, Zamanipoor Najafabadi AH, Schoones JW, et al. The impact of new evidence on regional variation in paediatric tonsillectomy and adenoidectomy: a historical review. J Laryngol Otol 2020;134:1036-43.

42 Specialisten FM. Otitis media bij kinderen in de tweede lijn, 2014.

43 Wennberg J. Small area variations in health care delivery. Science 1973;182:1102-8.

44 Rynnel-Dagöö B, Ahlbom A, Schiratzki H. Effects of adenoidectomy: a controlled two-year follow-up. Ann Otol Rhinol Laryngol 1978;87:272-8.

45 Ivers N, Jamtvedt G, Flottorp S, et al. Audit and feedback: effects on professional practice and healthcare outcomes. Cochrane Database Syst Rev 2012:Cd000259. 